\title{
Budget woes hinder clinical-trials network
}

\section{Costly cancer trials a challenge for revamped US programme.}

\section{BY HEIDI LEDFORD}

$\mathrm{F}$ ollowing years of criticism, a nationwide US cancer clinical-trials programme came to an end on 1 March. But many fear that the programme replacing it although designed to be nimbler and more focused - will be unable to conduct the types of trial needed in an era of expensive, personalized cancer treatments.

"We've got an exciting new structure and great science," says Monica Bertagnolli, an oncologist at the Dana-Farber/Brigham and Women's Cancer Center in Boston, Massachusetts, who serves on the new National Clinical Trials Network (NCTN). "But the severe budgetary constraints are forcing us to really limit what studies are being done."

For more than half a century, the Clinical Trials Cooperative Group Program, run by the US National Cancer Institute (NCI) in Bethesda, Maryland, has been the main government-funded mechanism for carrying out trials that drug companies avoid because the results are unlikely to boost profits. The programme has had notable successes: it helped to boost the cure rate of childhood cancers from less than $10 \%$ to almost $80 \%$; determined that the drug tamoxifen could halve the incidence of breast cancer in women at high risk of the disease; and found effective alternatives to radical mastectomies for earlystage breast cancers.

But the cooperative group programme has also been criticized for its inefficiency at a time when cancer research is advancing rapidly. Tumours have been divided into subtypes on the basis of their genetic mutations, and there is growing interest in testing tailor-made therapies. To achieve that, many patients must be screened to find those with the right cancer types.

In theory, the cooperative group programme, which included more than 3,000 institutions and some 14,000 investigators, could have provided the power and reach needed to find those patients. But a 2010 report by the US Institute of Medicine pronounced it unfit for the challenge. The institute found that many trials took so long to launch that, by the time they did, they no longer reflected cutting-edge science. Only about $60 \%$ of the programme's trials were ever completed.

In response, over the past four years, the $\mathrm{NCI}$ has been readying a replacement: the
NCTN. Ten cooperative groups have been consolidated to five, and there is now a unified system for data management and ethical review. The NCTN also has strict deadlines for trial initiation. "If a study doesn't meet those timelines, it's dead," says Bertagnolli. The time taken to start a large clinical trial has already dropped from two years to one - in line with the time it takes pharmaceutical companies to launch trials, says James Doroshow, deputy NCI director for clinical and translational research.

But the network's budget, just like that of the old programme, falls far short of those of its industry counterparts. The NCI reimburses member institutions by about US $\$ 2,000$ per enrolled patient - much less than the
"What if a critical scientific opportunity arises that cannot be addressed?" $\$ 20,000$ per patient that pharmaceutical companies provide, says Philip DiSaia, an oncologist at the University of California, Irvine, who was chair of a gynaecological oncology cooperative group. As a result, some institutions have threatened to pull out of the network, says DiSaia, and others have capped the number of patients they will enrol in an NCTN trial.

At some clinical-trial sites, the NCI plans to boost reimbursement rates to $\$ 4,000$ per patient. But that, combined with a flat budget, means that the NCTN will admit only 17,000 patients in 2014, down from 21,000 admitted last year under the old system. And that could limit the kinds of trials the network can take on, says Robert Comis, co-chair of an NCTN group and an oncologist at Drexel University in Philadelphia, Pennsylvania. "What if a critical scientific opportunity arises that cannot be addressed because of the quotas?"

\section{CORRECTION}

In the News Feature 'Smart enough to die?' (Nature 506, 284-286; 2014), it was the Virginia court system, not the US Supreme Court, that changed Daryl Atkins's sentence to life imprisonment. The Supreme Court also did not mandate that rulings on intellectual disability in death-penalty cases should follow the standards of the American Association on Mental Retardation. 